\title{
3. NEW HARD-ROCK DRILLING AND CORING TECHNIQUES TESTED AT SITE 648 DURING ODP LEGS 106 AND 109 $^{1}$
}

\author{
Shipboard Scientific Party ${ }^{2,3}$
}

\section{INTRODUCTION}

The difficult drilling conditions expected in fresh, young basaltic rocks and the technical problems associated with barerock spud-in led to several significant modifications of standard DSDP/ODP coring equipment and operating techniques in preparation for Legs 106 and 109. This report discusses the design and development of new hardware and techniques for crustal

${ }^{1}$ Detrick, R., Honnorez, J., Bryan, W., Juteau, T., et al., 1988. Proc. ODP, Init. Repts. (Pt. A), 106/109: College Station, TX.

2 Robert S. Detrick (Co-Chief Scientist), Graduate School of Oceanography, University of Rhode Island, Narragansett, RI 02882; Jose Honnorez (Co-Chief Scientist), Rosenstiel School of Marine and Atmospheric Sciences, University of Miami, 4600 Rickenbacker Causeway, Miami, FL 33149 (current address: Institut de Géologie, Université Louis Pasteur, 1 Rue Blessig, 67084 Strasbourg, France); Andrew C. Adamson (Staff Scientist), Ocean Drilling Program, Texas A\&M University, College Station, TX 77843; Garrett W. Brass, Ocean Drilling Program, National Science Foundation, 1800 G Street NW, Washington, DC 20550; Kathryn M. Gillis, Department of Geology, Dalhousie University, Halifax, Nova Scotia B3H 3J5, Canada (current address: Départment de Géologie, Université de Montréal, C.P. 6128, Succursale A, Montréal, Quebec H3C 3J7, Canada); Susan E. Humphris, Department of Chemistry, Woods Hole Oceanographic Institution, Woods Hole, MA 02543; Catherine Mevel, Laboratoire de Pétrologie Métamorphique, Université Pierre et Marie Curie, 4 Place Jussieu, 75230 Paris 05, France; Peter S. Meyer, Department of Geology and Geophysics, Woods Hole Oceanographic Institution, Woods Hole, MA 02543; Nikolai Petersen, Institute für Geophysik, Universität München, Theresienstrasse 41, D-8000 München 2, Federal Republic of Germany; Martina Rautenschlein, Max-Planck-Institut für Chemie, Abtellung Geochemie, Postfach 3060, D-6500 Mainz, Federal Republic of Germany; Tsugio Shibata, Faculty of Science, Okayama University, 3-1-1 Tsushimanaka, Okayama 700, Japan; Hubert Staudigel, Geological Research Division, Scripps Institution of Oceanography, University of California, San Diego, La Jolla, CA 92093; Anita L. Wooldridge, Marine Geology and Geophysics, University of Miami, 4600 Rickenbacker Causeway, Miami, FL 33149; Kiyohiko Yamamoto, Faculty of Science, Tohoku University, Sendai, Miyagi Pref. 980, Japan.

${ }^{3}$ Wilfred B. Bryan (Co-Chief Scientist), Department of Geology and Geophysics, Woods Hole Oceanographic Institution, Woods Hole, MA 02543; Thierry Juteau (Co-Chief Scientist), Laboratoire de Pétrologie, Université de Bretagne Occidentale, 6 Avenue Le Gorgeu, 29287 Brest, France; Andrew C. Adamson (ODP Staff Scientist), Ocean Drilling Program, Texas A\&M University, College Station, TX 77843; Laurie K. Autio, Department of Geology and Geography, Morrill Science Center, University of Massachusetts, Amherst, MA 01003; Keir Becker, Rosenstiel School of Marine and Atmospheric Sciences, University of Miami, 4600 Rickenbacker Causeway, Miami, FL 33149; M. Mansour Bina, Laboratoire de Géomagnetisme, Université Pierre et Marie Curie, 4, Avenue de Neptune, 94107 St. Maur des Fosses, France; Jean-Philippe Eissen, O.R.S.T.O.M., B.P. A5, Noumea, New Caledonia (current address: O.R.S.T.O.M., IFREMER, BP 337, 2273 Brest Cedex, France); Toshitsugu Fujii, Earthquake Research Institute, University of Tokyo, 1-1-1 Yayoi, Bunkyo-ku, Tokyo 113, Japan; Timothy L. Grove, Department of Earth, Atmospheric and Planetary Sciences, Massachusetts Institute of Technology, Cambridge, MA 02139; Yozo Hamano, Earthquake Research Institute, University of Tokyo, 1-1-1 Yayoi, Bunkyo-ku, Tokyo 113, Japan; Rejean Hebert, Departement de Géologie, Université Laval, Quebec G1K 7P4, Canada; Stephen C. Komor, Bureau of Mines, Avondale Research Center, 4900 LaSalle Road, Avondale, MD 20782 (current address: Department of Geology and Geophysics, University of Wisconsin, Madison, WI 53706); Johannes Kopietz, Bundesanstalt für Geowissenschaften und Rohstoffe, Stilleweg 2, D-3000 Hannover 51, Federal Republic of Germany; Kristian Krammer, Institut für Geophysik, Universität München, Theresienstrasse 41, D-8000 München 2, Federal Republic of Germany; Michel Loubet, Laboratoire de Mineralogie, Université Paul Sabatier, 38 Rue des 36 Ponts, 31400 Toulouse, France; Daniel Moos, Borehole Research Group, Lamont-Doherty Geological Observatory, Columbia University, Palisades, NY 10964; Hugh G. Richards, Department of Geology, The University, Newcastle upon Tyne NE1 7RU, United Kingdom. drilling and evaluates their performance on Legs 106 and 109. Preliminary recommendations are also made for future coring efforts at Hole $648 \mathrm{~B}$ or at other hard-rock sites.

The primary engineering objective during Legs 106 and 109 was to drill and advance a cored hole into freshly exposed basalt having little or no sediment cover. Secondary engineering objectives are listed in relative order of importance as follows:

1. Leave the hole (Hole 648B) in a stable and reenterable condition as an in-situ natural laboratory to allow deepening on successive legs.

2. Sufficiently advance the "hard-rock learning curve" to allow optimum performance at subsequent sites of this character.

3. Obtain core samples continuously from the seafloor to total depth.

4. Achieve a minimum total penetration of $400 \mathrm{~m}$ below the seafloor.

\section{PREVIOUS DSDP/ODP EXPERIENCE AT HARD-ROCK SITES}

Previous DSDP/ODP attempts to core fresh, young basalts with little or no overlying sediment cover have met with minimal success. Efforts to spud a coring assembly into unsedimented basalts using surface-driven rotation without lateral support for the drill string or bit confinement have usually resulted in failure to spud in or in damage to or catastrophic loss of the lower portion of the drill string.

At sites where sufficient sediment cover has been available to laterally support the lower drill string and allow penetration of the basalt substrate, severe hole instability, reduced penetration rates, and excessive core bit wear were observed. On frequent occasions the drill string became irretrievably stuck in the borehole, resulting in the loss of both the hole and the lower portion of the drill string. In addition, total core recovery has generally averaged less than $15 \%$.

\section{SPECIFIC DRILLING PROBLEMS ANTIPICATED FOR LEGS 106 AND 109}

Critical hard-rock drilling problems were identified from previous DSDP/ODP hard-rock site experiences and the drilling and coring conditions expected at the Leg 106/109 bare-rock site.

\section{Initial Entry}

Primary difficulties associated with spudding a hole into bare rock are (1) bit confinement, (2) bit energy and drilling action, (3) stabilization of the drill string above the seafloor, and (4) near-seafloor hole instability.

The hard-rock guidebase (HRGB) was designed to provide the primary means to counter natural and induced lateral bit forces. With the HRGB, the bit is held in a stationary position in contact with the seafloor until the hole is sufficiently deep for the borehole walls to provide lateral support. A near-seafloor rotational drive reduces the additional lateral forces affecting the bit from rotation of the entire drill string. 
To reduce the time that the bit is artificially confined, bit energy is maximized and drilling action enhanced. Applied bit weight must be kept below the level at which undesirable precessive motion of the lower drill string develops about the bit axis. To partially compensate for this low level of weight applied to the bit, rotational speeds of the bit must be maximized within the limitations of the bit bearings and cutting structure. The bit cutting structure must withstand the high-impact loading resulting from the rotational speed, yet exhibit sufficient insert extension to provide reasonable cutting action. Similarly, sufficient hydraulic energy must be available to keep the bit face clear of debris.

Surface and near-surface hole instability could occur if the seafloor crust is unconsolidated or easily fractured. Advancing the bit under such conditions in a drilling mode is believed to be more straightforward than coring for a given hole size. High annular lifting capacities are required to clear the borehole of drilled or sloughed debris, and there must be a reliable method of transporting such material away from the borehole at the seafloor level. Such unstable hole conditions require high levels of input torque for bit rotation. In addition, drilling jars are required in the drill string above the seafloor in case the bottomhole assembly (BHA) sticks.

If deteriorating hole conditions halt further drilling/coring progress or endanger salvaging the borehole, a portland cement slurry could be placed in the hole in hopes of consolidating mobile or sloughing rock materials. The hardened cement would then be drilled out of the borehole.

\section{Coring to Depth}

The primary problems associated with advancing the cored hole are (1) stabilizing the drill string above the seafloor, (2) further stabilizing the borehole to allow reasonably risk-free coring to be continued to depth, (3) providing drilling and coring systems to cut the hole to the objective depth within the time allotted, and (4) providing a permanent reentry structure for the hole.

Again, to prevent failure of the lower drill string members, eccentric motion and compressive loading of the drill string above the seafloor must be eliminated. Wireline retrievability of cored rock is mandatory, and effective bit and coring/drilling tool life must exceed $20-30 \mathrm{hr}$ of rotation.

\section{DESCRIPTION OF NEW CRUSTAL DRILLING AND CORING SYSTEMS}

The problems outlined above were addressed for Legs 106 and 109 by development of the HRGB in conjunction with an integrated drilling and coring program that reduces the need for stabilization of the drill string above the seafloor, provides wireline retrievability of cored rock, and optimizes equipment performance and durability in meeting leg objectives.

Additional design constraints for the Leg 106/109 drilling/ coring program were:

1. Compatibility with the proposed bit constraint/reentry structure (HRGB).

2. Compatibility with existing sonar and/or proposed sonar/television reentry systems.

3. Compatibility with existing ODP drilling and coring equipment and techniques.

4. Core diameter sufficient to meet scientific requirements.

5. Delivery time and project schedule requirements.

6. Technical soundness, simplicity, convenience of handling, proven subconcepts, and durability.

7. Budget constraints.

\section{Hard-Rock Guidebase Design}

The HRGB was designed to provide a temporary reentry structure capable of confining the bit during spudding operations and supporting the load of a permanent gimbaled reentry cone and all casing strings. The HRGB can be deployed in up to $6000 \mathrm{~m}$ of water and is designed to land on seafloor sloping from $0^{\circ}$ to $20^{\circ}$ with up to 1 -m-diameter boulders present. The HRGB is a box-shaped structure that stands on four legs. The overall dimensions are $8 \mathrm{ft}(2.4 \mathrm{~m})$ long by $7.5 \mathrm{ft}(2.3 \mathrm{~m})$ deep by $10.8 \mathrm{ft}(3.3 \mathrm{~m})$ high (Fig. 1). The base is constructed in halves ( 8 $\mathrm{ft}(2.4 \mathrm{~m}) \times 7 \mathrm{ft}(2.1 \mathrm{~m}) \times 17 \mathrm{ft}(5.2 \mathrm{~m}))$ for ease of shipping and handling. Prior to deployment, the halves are bolted together and the legs attached. The guidebase cone is $16 \mathrm{ft}(4.9 \mathrm{~m})$ in diameter and $6 \mathrm{ft}(1.8 \mathrm{~m})$ deep. A 31-in.-diameter opening in the guidebase permits the 26-in.-diameter conductor pipe on the gimbaled reentry cone to be inserted vertically into the HRGB seated on seafloor (Fig. 2).

The HRGB is divided by transverse and longitudinal bulkheads into four isolated compartments (Fig. 3). The guidebase halves are bolted together along the longitudinal bulkheads. The diagonal bulkheads structurally reinforce each compartment. The individual compartments ensure that if the guidebase exte-

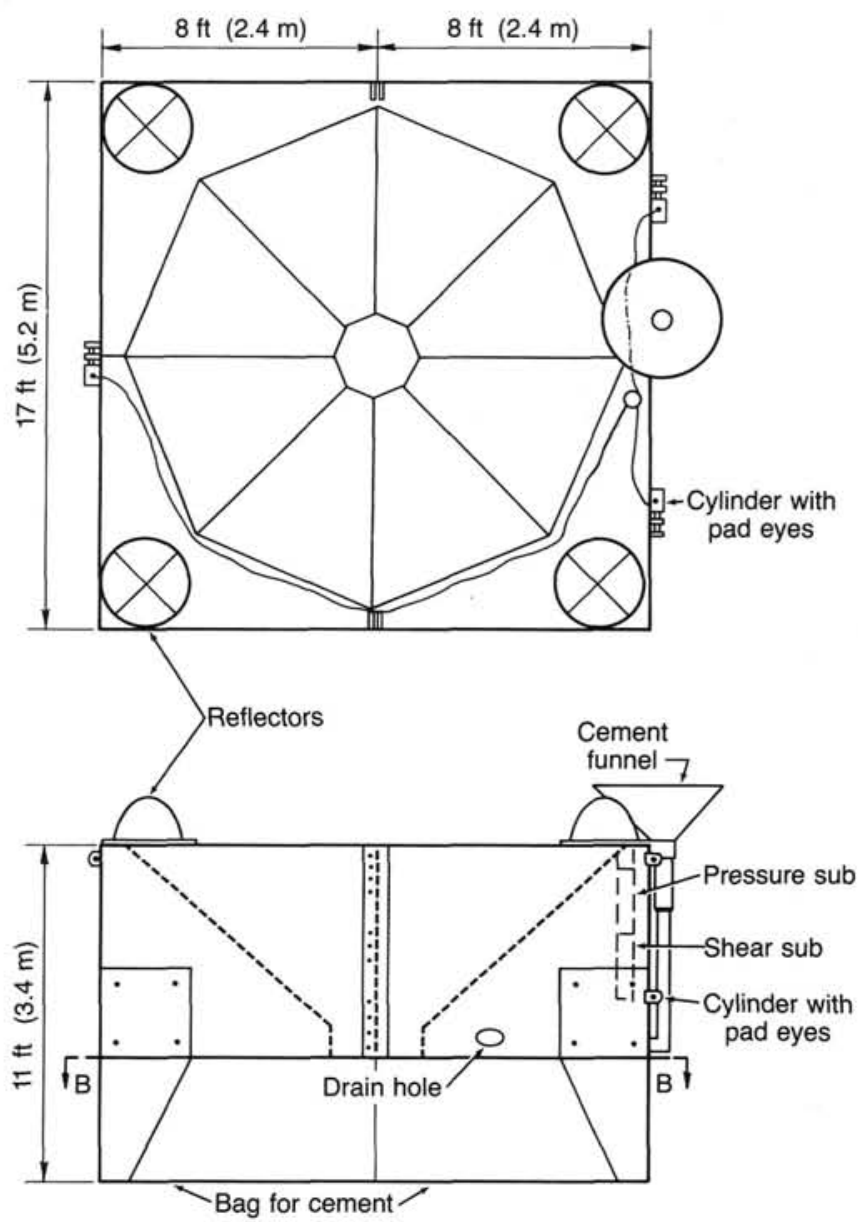

Figure 1. Top and side views of the HRGB. The $18,000-\mathrm{kg}$ guidebase stands on four legs and is $5.2 \mathrm{~m}$ square and $2.3 \mathrm{~m}$ high. The cone inside the guidebase is $16 \mathrm{ft}(4.9 \mathrm{~m})$ in diameter and $6 \mathrm{ft}(1.8 \mathrm{~m})$ deep. See Figure 3 for section B-B. 


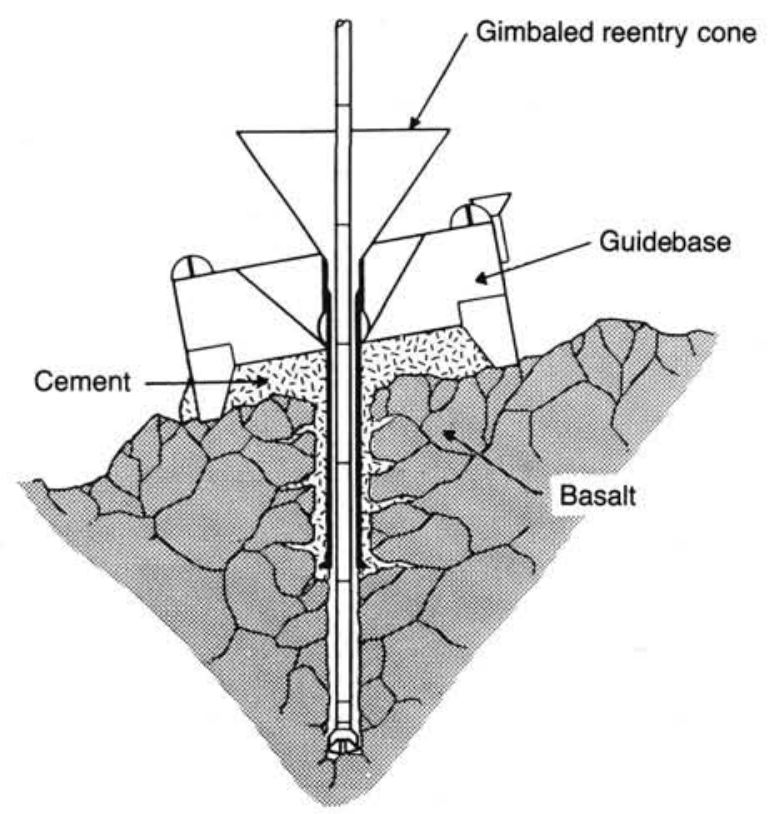

Figure 2. The HRGB developed for Legs 106 and 109 to provide the lateral support necessary for the drill bit to spud-in to hard, volcanic rock on seafloor with little or no sediment cover.

rior is damaged during deployment, at least a portion of the guidebase can be filled with cement.

A cement manifold in one half of the base distributes cement to each of the four compartments. As the cement in each compartment fills to a depth of $3 \mathrm{ft}(1 \mathrm{~m})$, it enters overflow pipes that connect to bags installed underneath the base. The cement in the HRGB compartments weights and structurally supports the cone. The cement in the bags underneath provides lateral constraint and is also used to consolidate the boulders and rubble under the base. The guidebase weighs $18,000 \mathrm{~kg}$ on the seafloor. Cement inside the guidebase increases the weight to 36,000 $\mathrm{kg}$. An additional $27,000 \mathrm{~kg}$ (combined weight) is contained in the four bags of cement for a total weight of $63,000 \mathrm{~kg}$.

The guidebase has a special gimbaled reentry cone (Fig. 4). The lower cone section has a gimbal in place of the 8 - $\mathrm{ft}(2.4 \mathrm{~m})$ mud mat attached to a standard reentry cone. The gimbal can be positioned at any point on the 26 -in. conductor housing, as determined by hole conditions and the attitude of the HRGB. The purpose of the gimbal is to provide adequate contact surface to support the reentry cone at up to $12^{\circ}$ inclination of the HRGB. For angles up to $20^{\circ}$, the reentry cone and the 26-in. conductor casing combination provides enough surface contact for adequate support. Due to the $12^{\circ}$ support limit of the gimbal, setting the guidebase on a slope of less than $12^{\circ}$ provides optimum stability.

When spudding the 18-1/2-in.-diameter hole through the HRGB, the axis of the drilled hole must be along the same axis as the opening in the HRGB. Without this alignment, the casing would bind up against the side of the 31 -in. diameter opening in the guidebase and could not be run in the hole. A drill bushing 24 -in. O.D. by $10-1 / 2$-in. I.D. and approximately $6 \mathrm{ft}(1.8 \mathrm{~m})$ long, that slides onto the drill motor and rests on top of the bit, travels down with the bit on reentry and slides into the 31 -in. diameter opening in the guidebase. The bushing centralizes the drilling motor and 18-1/2-in. drill bit while the upper section of the hole is drilled. The drill bushing can be removed from the BHA once the upper section of the hole is established.
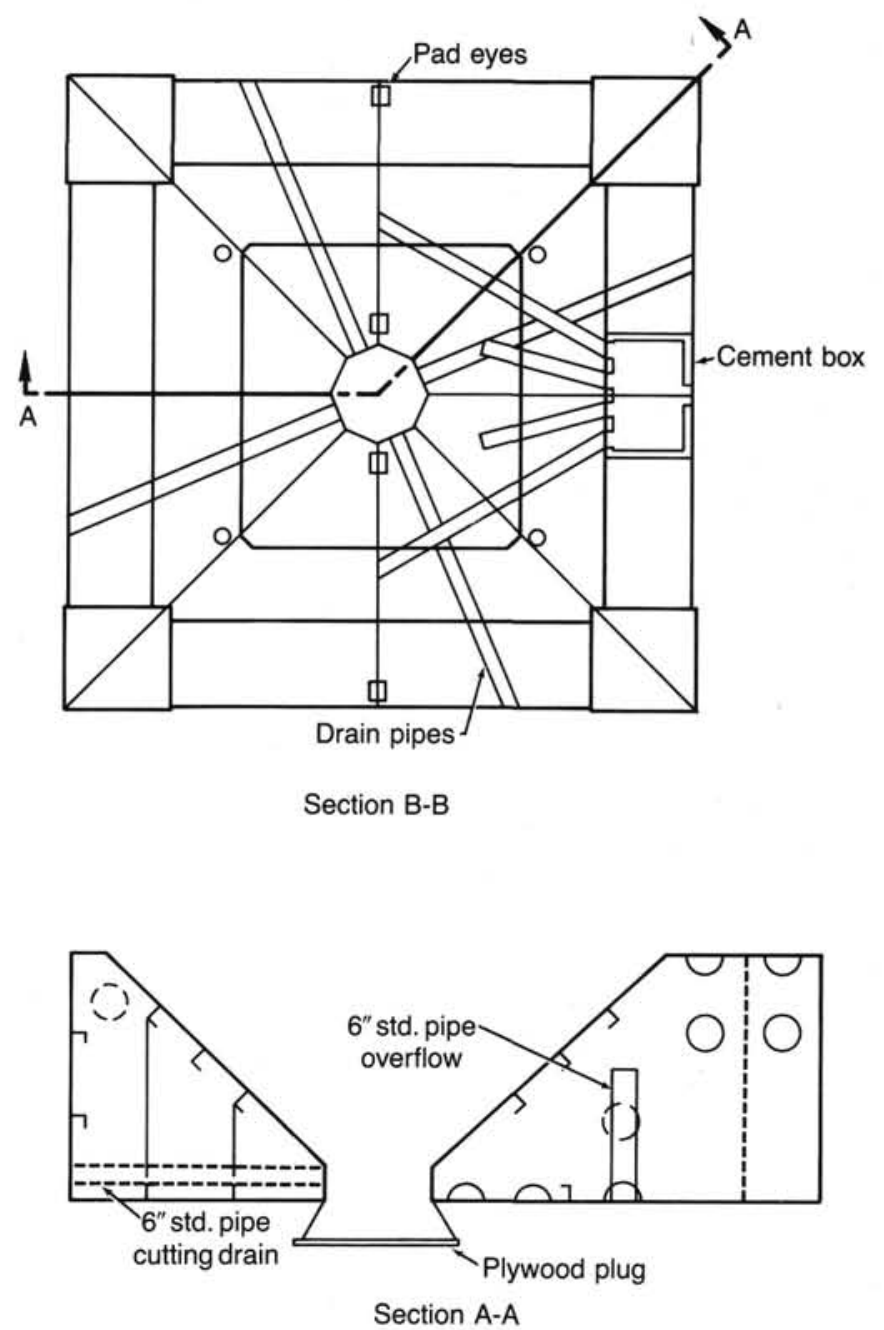

Figure 3. The internal structure of the HRGB showing the four compartments separated by transverse and longitudinal bulkheads.

\section{Methods for Deployment of the HRGB}

A running and cementing system was developed to deploy, run, land, and release the HRGB on the seafloor. The base is assembled on its side from halves in the moon pool, run through the moon pool vertically on two running cables, and leveled to the horizontal running position on three cables once it is below the keel of the ship (Fig. 5). Release cylinders attach the 1-1/2in. running cables to large pad eyes at three points on the guidebase. Each cable is attached to the release cylinder piston rod which in turn extends into a second pad eye locking the cables in place. To prevent the release cylinders from being activated by pressure surge in the drill pipe (caused by heave) while running the HRGB to the seafloor, shear bolts and washers secure the ends of the piston rods to the pad eyes. Approximately 68 atmospheres of pressure must be applied to the release cylinder to cause the shear bolt to fail and free the piston rod, allowing the cable to be released from the HRGB.

The release cylinders are connected with hydraulic hoses to the pressure-shear sub assembly. The kelly hose is attached from the bottom of the running sub to the top of the pressure-shear sub assembly. The pressure-shear sub assembly consists of a manifold sub for supplying fluid to the release cylinders, a pres- 


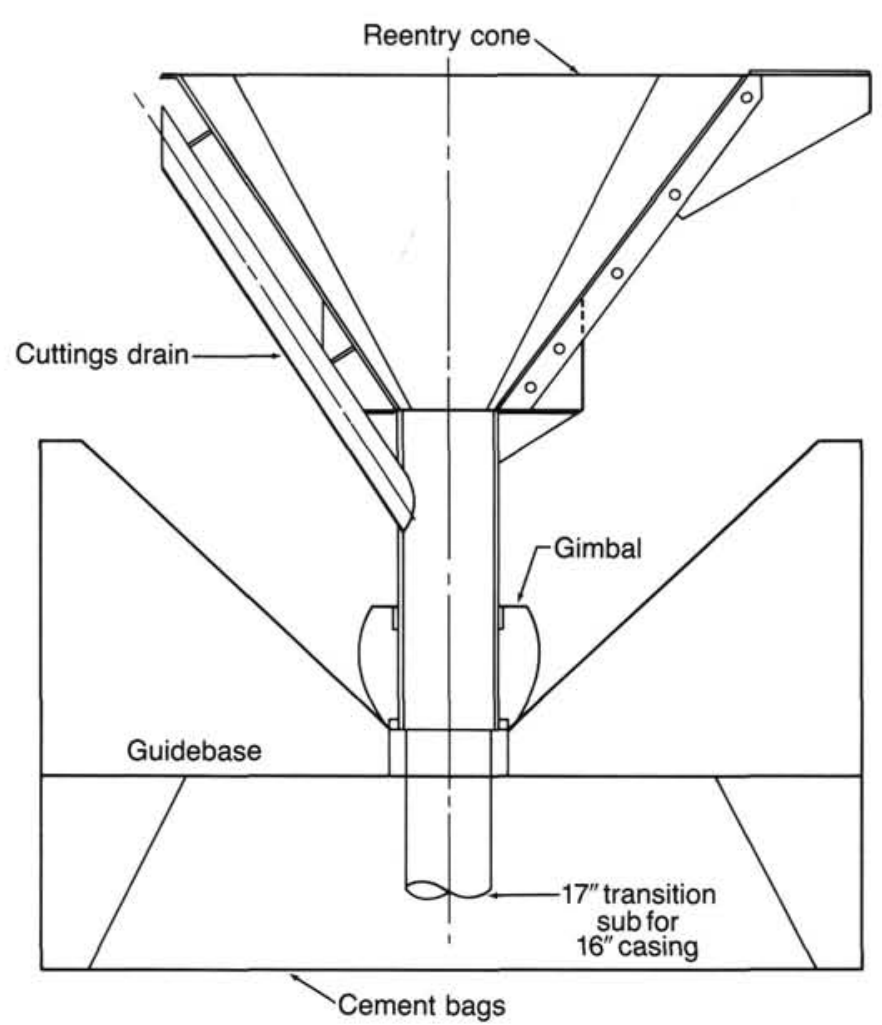

Figure 4. Gimbaled reentry cone designed for the HRGB.
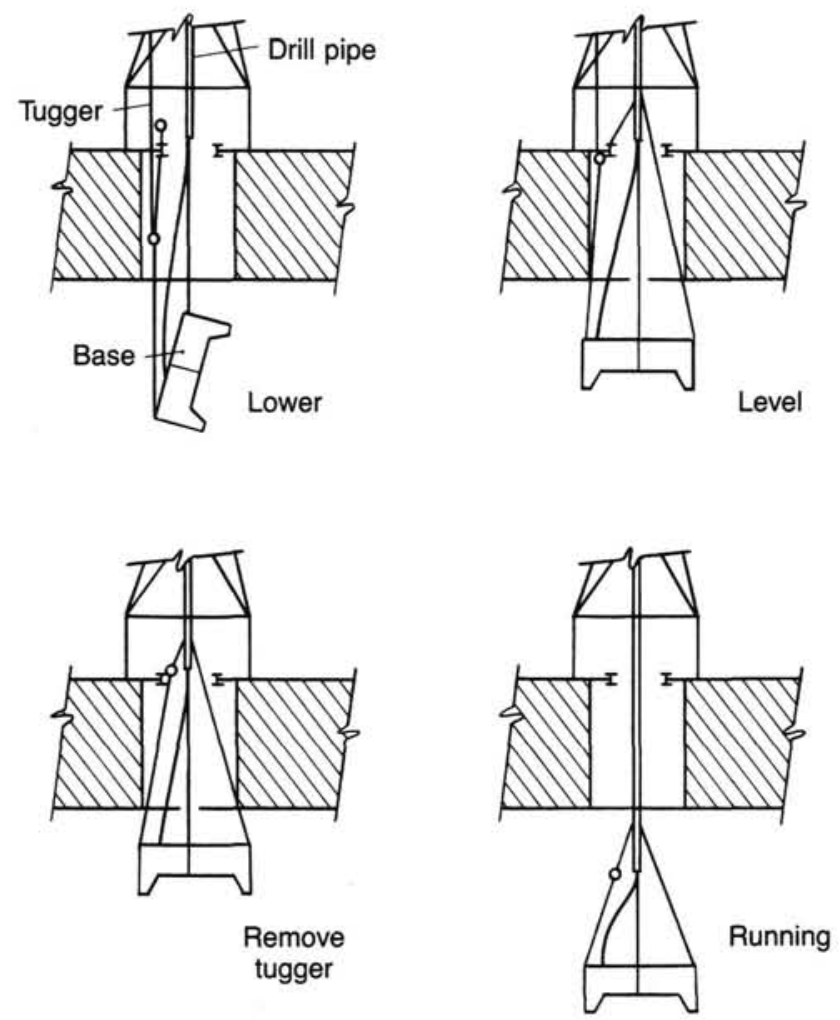

Figure 5. Deployment procedure for the HRGB. See text for discussion. sure sub used for activating the release cylinder and a shear sub used to retract the kelly hose from the guidebase (Fig. 1).

Once the HRGB has been lowered to the seafloor, readings from an acoustic tilt beacon and mechanical tilt indicator mounted on the guidebase are taken to determine that the HRGB is sitting at less than a $20^{\circ}$ inclination (with an inclination of less than $10^{\circ}$ preferable). The acoustic tilt beacon also is used as a positioning beacon for making reentries into the HRGB. When the inclination of the guidebase is established as suitable, the cable releasing sequence is started (Fig. 6).

To pressure up the release cylinders the fluid passage into the cement manifold in the guidebase must be closed off by dropping a 2-1/2-in.-diameter Kirksite (metal alloy) ball into a seat in the pressure sub. The drill string can then be pressured up because the ball seals off the flow path through the pressure sub. The cement pump is used to activate the release cylinders because more flow control (volume and pressure) can be maintained than with the triplex mud pumps. After reaching a 68-atmosphere pressure differential across the release cylinders the shear screws will fail, allowing the piston rods to retract, which releases the running cables. The pressure is then increased to 272 atmosphere, which shears ten steel screws in the pressure sub, causing the ball seat to shift downward and release the ball to be pumped through the pressure-shear sub assembly and into the HRGB cement manifold.

Cement is then pumped down the drill string through the kelly hose and into the HRGB cement manifold. When the cement reaches a depth of $3 \mathrm{ft}(1 \mathrm{~m})$ inside the base, the cement is carried by the overflow pipes down into the four cement bags underneath the base. After pumping a total of $57 \mathrm{~m}^{3}$ of cement into the guidebase, the kelly hose is severed from the guidebase with a shear sub. The shear sub can be set at different loads by
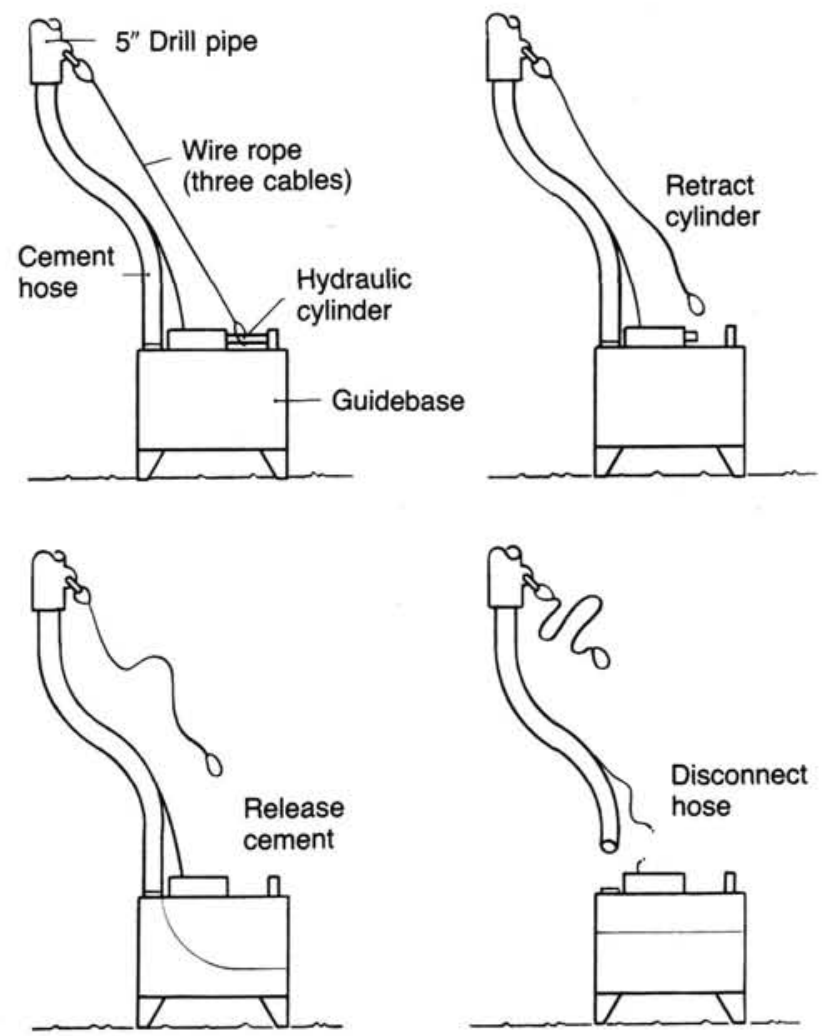

Figure 6. HRGB landing and cementing sequence. See text for discussion. 
varying the number of shear screws. Selection of the shear load for the guidebase must take into consideration that the shear sub can be activated without cement in the guidebase. The shear load is therefore set at some value less than $16,000 \mathrm{~kg}$ (weight of HRGB in water). The maximum shear load is determined to be $13,600 \mathrm{~kg}$, which takes into account the weight of the HRGB and the angle the kelly hose would be pulled from if the base were sitting at the maximum allowable $20^{\circ}$ angle. Upon activating the shear sub with up to $13,600 \mathrm{~kg}$ of drill string pull, the pressure-shear sub assembly and kelly hose are retrieved to the surface with the drill string.

A number of contingency plans were developed in case of running, releasing, or cementing hardware failure. In the event the release cylinders could not be activated, a backup release sequence would involve using the television system and the ship's dynamic positioning system to offset the ship so that the running cables can be positioned away from the guidebase. The running sub can then be lowered to the seafloor and severed from the drill string with an explosive charge. In a similar manner, if the shear sub cannot be activated with drill string pull to remove the kelly hose from the guidebase, a severing charge could be used. The kelly hose separating from the HRGB prematurely can be remedied by tripping the drill pipe to attach a stinger to the bottom of the drill string. The drill pipe would then be tripped back in the hole. An emergency cement funnel $3 \mathrm{ft}(1 \mathrm{~m})$ in diameter is mounted on the HRGB. Using the television system and the ship's dynamic positioning system the stinger can be stabbed into the cementing funnel. Cement is then pumped through the drill string, into the cementing funnel and into the guide base.

\section{Modifications to Design and Deployment Plans Made Before Deployment on Leg 106}

During the transit from St. John's, Newfoundland, to the drilling site (Site 648) during Leg 106, some modifications were made to the HRGB and to the handling and running procedure proposed by SEDCO. The tilt beacon was moved from the outside to the inside of the guidebase, to prevent the tilt beacon from being damaged while lowering the guidebase through the moon pool. Modifications were made to the cementing funnel to prevent the lower running cable from being fouled while handling the base through the moon pool. A clamp assembly was made for the pressure-shear sub assembly to prevent it from rotating during deployment and possibly damaging the release cylinder hydraulic lines connected to it.

\section{Borehole Design: Leg 106}

The existing ODP multiple casing system, utilizing sequential strings of $20-, 16-$, and 11-3/4-in. O.D. casings with a terminal bit size of $9-7 / 8$ in., is the dominant criterion for borehole design. Existing techniques, however, did not allow casing to be set a significant distance into hard rock and was limited to only a $9-7 / 8$-in. bit size below the basalt contact. It was therefore clear that in order to take advantage of as many existing ODP drilling and coring systems as possible, considerable retrofitting and special tool design was required.

\section{Casing Point Selection}

The primary functions of the first and shallowest casing string are: (1) to permanently anchor the temporary guidebase to the seafloor, thereby providing for unimpeded access to the underlying hole; and (2) to isolate the hole from "loose" or unconsolidated rubble at or near the seafloor. An arbitrary casing point of approximately $30 \mathrm{~m}$ below the seafloor was specified. However, considerable flexibility was desirable in setting the casing in order to avoid a premature reduction in hole size and re- sulting termination of coring efforts. Opposing this need for flexibility and multiple casing strings was the accompanying requirement to be able to drill and maintain a series of large diameter holes in the basalt. The larger-diameter boreholes reduce efficiency in hole cleaning and increase the likelihood of hole instability problems that are proportional to hole size.

For these reasons, only two casing strings are realistically feasible, with the larger diameter 16-in. O.D. casing serving as the conductor and the 11-3/4-in. O.D. casing providing surface casing protection to some arbitrary depth. A 11-3/4-in. casing point of at least $100 \mathrm{~m}$ below the seafloor was used for design purposes. Figure 7 schematically presents the proposed hole and casing program for this Leg 106/109 hard-rock hole (Hole 648B).

\section{Hole Size Determination}

Hole sizes were chosen marginally large enough to allow the appropriate casing string to be run, recognizing that the hole would be drilled with an unstabilized or "slick" 8-1/4-in. O.D. drill collar string. This practice normally results in an effective hole diameter less than the nominal bit size due to the "wandering" or offsetting motion of the bit through a rock sequence of varying drillability. Each successive bit size would be as small as possible, considering the drift diameter of the previous casing string, bit availability, cost, penetration rate, hole cleaning, fishing implications, etc. Although the hole diameters selected (181/2-in., 14-1/2-in., and 10-1/2-in.) offer fair flexibility for unexpected hole conditions, the fixed constraints as outlined would result in significant compromises.

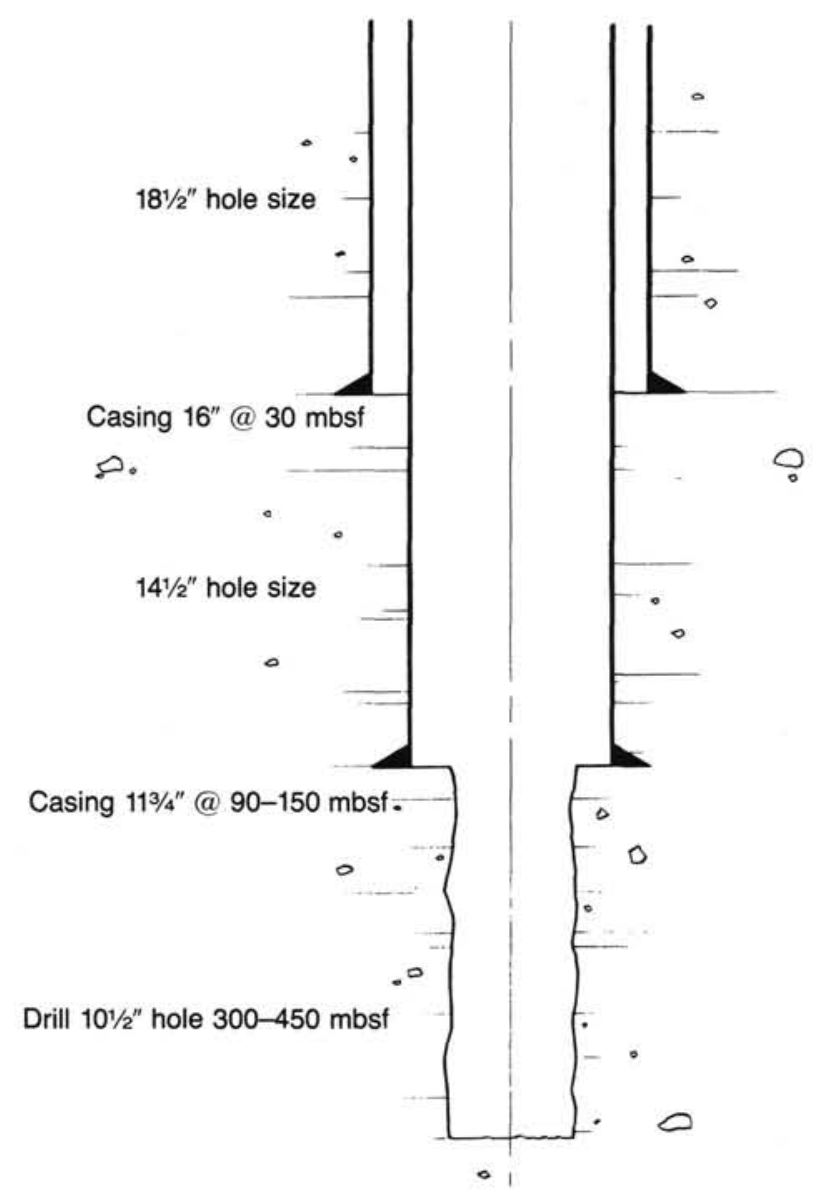

Figure 7. Proposed hole and casing program for Hole 648B. 


\section{Hard-rock Drilling Systems-Design and Development}

The Leg 106/109 hard-rock site required several major departures from the typical drilling and coring systems used by ODP. This was primarily due to the lack of any seafloor sediment cover to support the lower drill string for operations requiring bit rotation, the comparatively larger hole sizes to be drilled in hard rock, and hole instability characteristic of fresh basalt.

The drill string used for this site had to be modified to include a significant portion of 5-1/2-in. drill pipe on top of the more customary 5 -in. drill pipe string used for these depths to allow a surface load of nearly three times the weight of the string to be applied in an emergency. However, the length of the drill collar string used to load the bit had to be dramatically reduced to $10 \%-20 \%$ of the normal length for the appropriate bit size. This measure was used in an effort to prevent compressive failure of such tools while they were laterally unsupported above the seafloor.

Bit rotation was provided by a positive displacement motor placed just above the bit, in contrast to the normal method of turning the bit and the entire drill string from the surface with the top drive. This was done to prevent most of the eccentric or precessive motion of unsupported drill collars about the bit axis and the previously experienced drill string failures.

Drilling bits (18-1/2-in.) specifically designed to be driven at relatively high speeds in the hard abrasive basalt were chosen. Due to the high cost of these bits and the lack of performance data for use in basaltic rock, a conservative cutting structure was selected, which would be capable of respectable performance for the life of the bit bearings as opposed to a more aggressive structure that might fail considerably earlier, even though providing an improved penetration rate. In other words, the amount of hole penetration provided per bit was the overriding design factor as opposed to the penetration rate.

Similar design logic was used for the 14-1/2-in. O.D. and 10$1 / 2$-in. O.D. coring bits. As the hole is deepened, additional lengths of laterally supported drill collars can be added for bit loading. Cutting structure design thus becomes more responsive to bit weight. Similarly, as the hole size is reduced, less fluid volume would be necessary for flushing, resulting in a direct reduction in motor/bit rotational speed and allowing the use of more aggressive cutting structures.

Extremely high pumping rates are required to counter the natural slip velocity of drilled cuttings or sloughed rock fragments in the annular flow stream between the drill string and the borehole walls. Modifications to the mudpump delivery capability were made to provide a pump output of from five to ten times the normal volume used on the typical smaller-diameter ODP holes. Additionally, the capability to periodically mix and pump a volume of highly increased viscosity seawater is required to clear the hole of the larger rock fragments.

Due to the extreme value of this hole and the precarious operating conditions, fishing tools were specially designed to clear the hole of drilling equipment left in the hole. Because of the unstable hole conditions expected, the capability to temporarily "heal" or consolidate the borehole walls until they could be isolated with casing was required. If necessary, a cement slurry could be pumped into the borehole and, due to its density (nearly twice that of seawater), infiltrate the natural permeability and irregular shape of the hole. After sufficient setting time for the cement to attain a respectable compressive strength, the borehole would be drilled again.

As a last defense against loss of the drill string in the borehole, a set of hydraulically actuated drilling jars was included in the drill collar string above the seafloor. This tool was used to repeatedly transfer the potential energy stored in a highly ten- sioned drill string into a very sharp impact blow that is in excess of the tensile strength of the supporting drill pipe string.

\section{Hard-rock Coring Systems-Design and Development}

All rotary coring systems conventionally used by the DSDP/ ODP rely on surface-driven rotation. In order to avoid rotating a substantial length of laterally unsupported drill collar string, especially while loaded in a compressive mode, other means of driving the core bit are required. This must be without loss or modification to a substantial portion of the existing system functions such as wireline retrievability of cored rock, television-sonar reentry techniques, casing, and bit programs.

\section{Coring Motor}

To satisfy this requirement for Legs 106 and 109 , proven positive-displacement motor technology was integrated with reliable mining/coring technology to produce the first coring motor system capable of cutting and retrieving a 9-m-long core sample larger than 2-1/4-in. O.D. Figure 8 outlines the principal components of this coring motor.

The performance specification of the coring motor required using a multiple-lobe, positive displacement motor assembly to reduce the bit speed to be compatible with the sealed friction bearings and the brittle tungsten-carbide-insert cutting structure

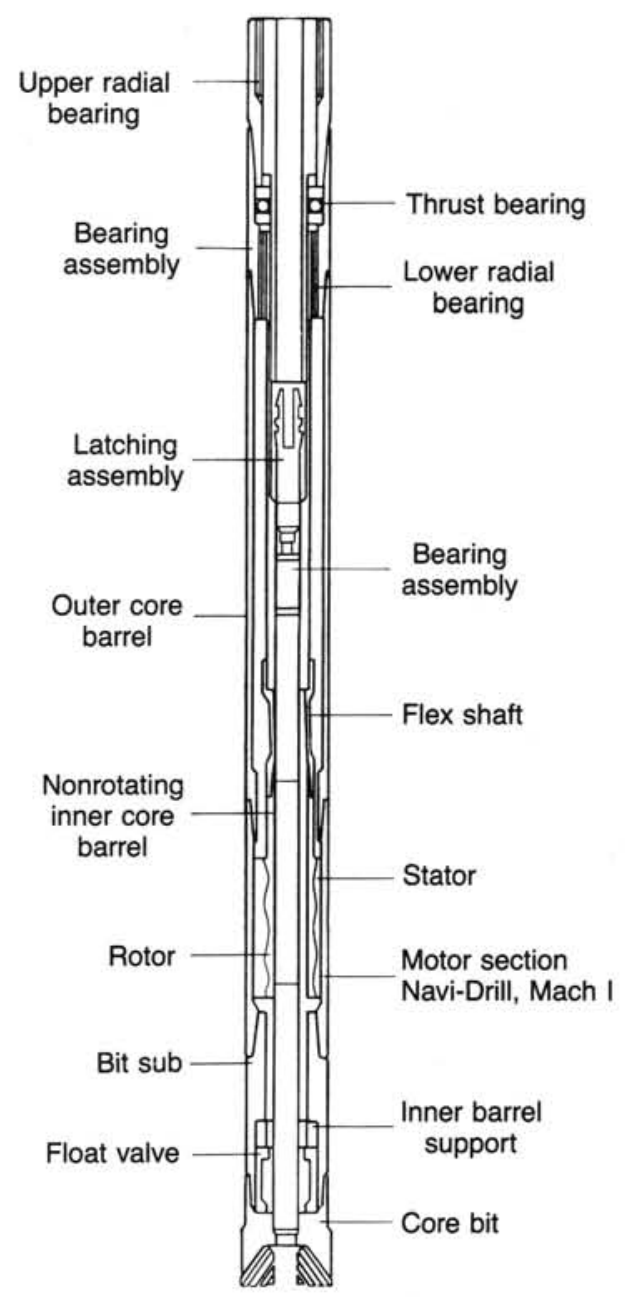

Figure 8. Outline of the principal components of the $9-1 / 2-i n .(24 \mathrm{~cm})$ Mach I Navi-Drill coring motor. 
of the core bits. Similarly, the output torque and thrust-bearing capacity of the motor allows for bit loading well in excess of the bit-bearing capacity and for nearly $25 \%$ of the torsional value required to damage the drill-pipe tool joints. The wide operating range of the motor permits fluid-flow rates well above those needed to properly clean even the largest holes to be cored.

The wireline core barrel retrieval system is compatible with existing ODP deployment systems. A variety of core catchers and shoe assemblies are available to optimize core recovery in the hard, broken, and abrasive basalt. The inner core barrel, without the commonly used plastic liners, was plated with chromium to reduce core jamming and the resulting poor recovery. Inner barrel deployment and retrieving systems are not as massive as the conventional ODP equipment, but are ruggedly designed for strength, simplicity, and durablility exceeding mining application specifications.

\section{Rotary Core Barrel}

Once the hole had been cored sufficiently deep for surfacedriven systems to be safely implemented, the conventional ODP rotary core barrel (RCB) would replace the coring motor. The advantage of this system is the ample experience in its use. The durable and dependable RCB may eventually serve to deepen the hole on later legs to the maximum desired depth.

\section{Contingent System}

Should the prototype system not perform as planned before the hole is deep enough to allow surface-driven rotation, a standard positive displacement drilling motor of the type used initially to establish the hole would be used to drive the conventional RCB system. Although this system would core safely until deep enough to use the top drive, wireline retrieval of the cored rock would be precluded, and the smaller diameter hole cut by the RCB system would have to be enlarged before installing the 11-3/4" casing string. The contingent system, though inefficient, would allow coring to continue.

\section{SUMMARY OF OPERATIONS ON LEG 106 AND 109}

\section{Site 648}

Assembly of the HRGB in the moon pool on Leg 106 was accomplished in $17 \mathrm{hr}$ with few problems under difficult weather conditions. Deteriorating weather conditions (swells 3-4 m, occasionally $4.6 \mathrm{~m}$ ) caused a 4-day delay in deployment. The HRGB was finally deployed with seas running $2.4-2.7 \mathrm{~m}$; the operation was accomplished very smoothly in $26 \mathrm{hr}$.

All HRGB running, release, and cementing systems worked as designed. The tilt beacon to determine HRGB attitude on the seafloor was very effective and is considered critical for proper guidebase pracemeni. When the HRGB kelly cementing hose separated, the guidebase moved up and shifted slightly. Modification to the pressure-shear sub release assembly will be needed to ease this problem. When the HRGB was run on Leg 106, optimum placement of the guidebase on the seafloor was not achieved. It was impossible to see below the HRGB with the television system while lowering it to the seafloor on the drill pipe. In order to optimize placement of a guidebase in the future, a means of viewing the seafloor under the guidebase with the television system is necessary.

The initial Leg 106 drilling program for Hole 648B called for the hole to be spudded in with a 18-1/2-in. diameter (Hughes X77) hard-formation drill bit (Fig. 7). Approximately $30 \mathrm{~m}$ of hole was to be drilled, and a shallow string of 16 -in. conductor casing was to be set anchoring the HRGB in place. At this point, coring was to commence with the 14-1/2-in. x 2-1/4-in. core bits. A second string of 11-3/4-in. casing was to be set at a depth determined by drilling conditions (90-150 mbsf). Upon setting the second string of casing, coring would continue with $10-1 / 2$-in. x 2-1/4-in. core bits. Both the 14-1/2-in. and 10-1/2in. core bits were to be utilized with the positive displacement coring motors (PDCM)..

Because of the highly unstable hole conditions, it was necessary to drill a pilot hole using first a 12-1/4-in. tricone bit and then a 9-7/8-in. core bit, each driven by a positive displacement drilling motor (PDM). Due to the highly abrasive and fractured rock, two 18-1/2-in. drill bits, one 14-3/4-in. drill bit, one 12-1/ 4 -in. drill bit, and one 9-7/8-in. core bit were expended to establish $15 \mathrm{~m}$ of 18-1/2-in. diameter hole. The 16-in. conductor casing was run and cemented to a depth of approximately 7.6 mbsf.

In an effort to improve drilling performance, a major alteration in the hole program became necessary (Fig. 9). Considera-

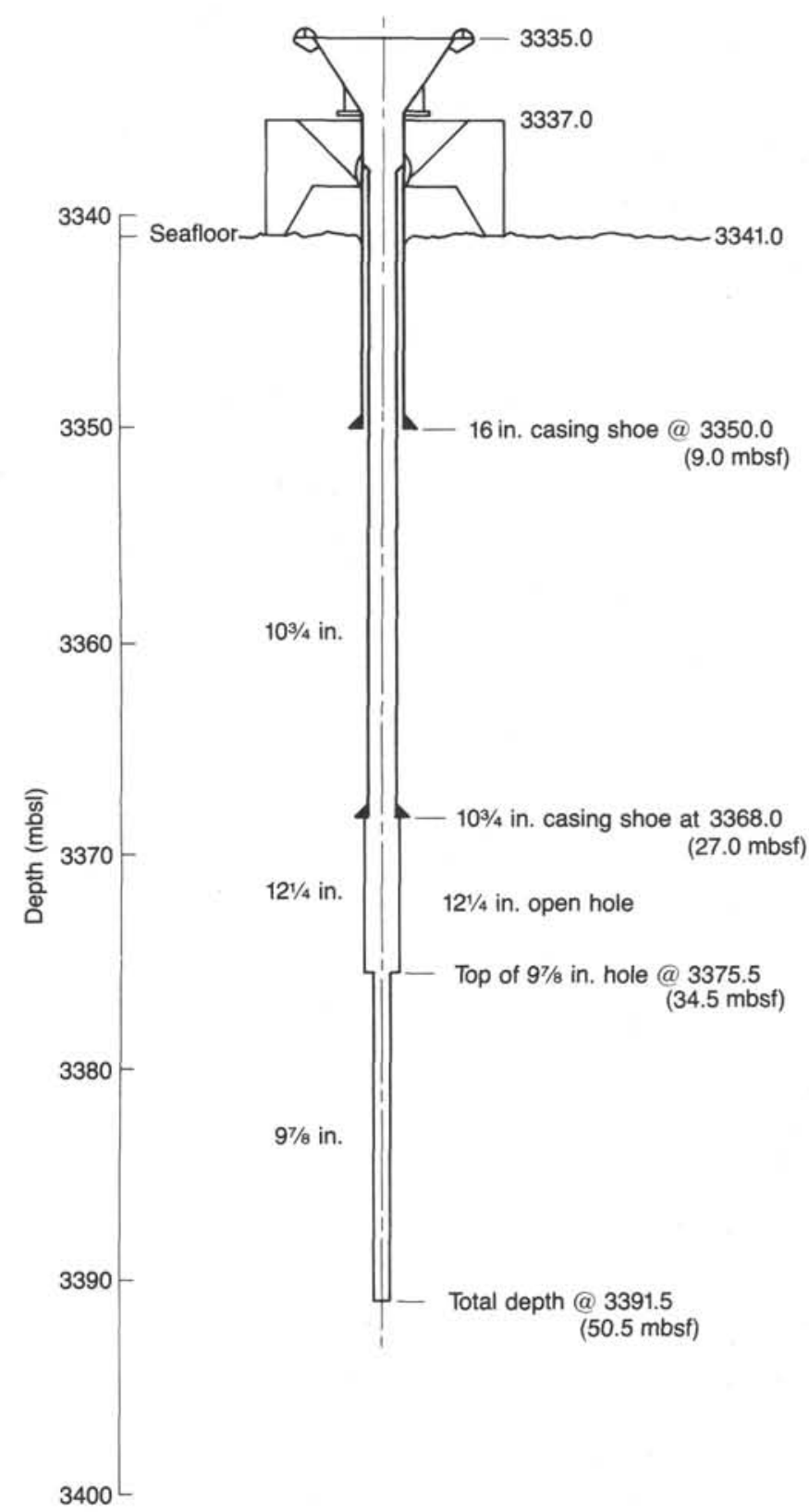

Figure 9. Actual hole configuration of Hole 648B. 
ble hole stability and progress was observed when coring the pilot hole with the 9-7/8-in. core bit. A conservative approach was adopted whereby a 9-7/8-in. cored hole was cut to approximately 33.5 mbsf to test hole conditions using a drill string combination offering considerable less exposure than the 14$1 / 2$-in. coring assembly. Hole conditions deteriorated no further across this interval of the hole and in fact improved somewhat. An effort was subsequently made to open the 9-7/8-in. hole to 14-3/4-in. to allow the 14-1/2-in. coring operations. Hole conditions again deteriorated. After reaching a depth of $26 \mathrm{mbsf}$, an open-hole cement plug was placed in an attempt to stabilize the hole. Little improvement was observed drilling out the plug, and operations were temporarily suspended to avoid irretrievably sticking the drill string in the hole. A total depth of 34 mbsf was reached in 25 days of drilling and coring.

Drilling and coring smaller hole sizes resulted in both increased penetration rates and hole stability during operations in Hole 648 B on Leg 106. Emphasis was therefore placed on reduced hole sizes, reduced hole annuluses, and specialized cementing techniques for improving hole stability during operations on Leg 109. To reduce hole sizes, 10-3/4-in. casing with special flush joint connections was run in place of the 11-3/4in. casing originally proposed. This allowed a reduction in hole diameter from 14-3/4-in. to 12-1/4-in. Drill collars 9-1/2-in. in diameter were run with 12-1/4-in. drill bits to reduce the size of the hole annulus. The reduction in hole annulus was observed to increase hole stability and improve the hole cleaning with the limited volumes of viscous bentonite and XP polymer sweeps that could be pumped. Reduced hole annuluses also helped to prevent rubble from falling down the hole on top of the bit.

Although improvements over Leg 106 operations were observed using the 12-1/4-in. bits and 9-1/2-in. drill collars, considerable torque was still required to maintain bit rotation. The sticking hole conditions prevented effective rotation of the bit with the torque available for safe operation. The bit stalled continuously at $40-60 \mathrm{rpm}$, but when the speed was increased to $120-180 \mathrm{rpm}$, the momentum from the large-diameter drill collars helped to maintain rotation of the bit, and a penetration rate of $1.2 \mathrm{~m} / \mathrm{hr}$ was realized. Though good progress was made using this drilling technique, the drilling jars failed twice to release stuck pipe, resulting in two time-consuming fishing jobs.

Owing to the high risk associated with drilling with the 121/4-in. bits, it was decided to make several 9-7/8-in. core bit runs. If it appeared after a core bit run, or several runs, that it was not possible to make acceptable progress in the hole, the time (3-5 days) and effort required to set the casing would be utilized for some other leg objective. Six core bit runs were made successively. Progress was significantly hindered by rubble falling back into the hole at the end of each bit run. On subsequent coring runs, the entire length of the hole had be redrilled and recored back to the depth reached by the previous core bit before making any new hole. A point was reached where the time required to drill and core the rubble zone to get back to bottom approached that of the rotating life of a 9-7/8-in. coring bit.

A 12-1/4-in. bit run was made to clean out the existing 121/4-in. hole as deep as possible. A depth of $3370 \mathrm{~m}$ ( $29 \mathrm{mbsf}$ ) was reached. The hole was filled with cement and a 12-1/4-in. bit run was made with a 12-1/4-in. roller reamer assembly. The $12-1 / 4$-in. reamer assembly was run to remove any ledges in the hole that might prevent the casing from being run to bottom. Upon completing the reaming operation, the 10-3/4-in. casing string was made up, run in the hole, and cemented in place. A 9-7/8-in. tricone bit was used to drill out the casing shoe and clean the hole out to a depth of $3388 \mathrm{~m}$. Several check trips were made from the bottom of the casing to the bottom of the hole and encountered no rubble or fill. It appeared that the 10-3/4in. casing isolated a major source of rubble. During a subsequent 9-7/8-in. core bit run, the bit became stuck at $3391.5 \mathrm{~m}$. It appeared that a rock, or possibly a core bit cone lost on an earlier bit run, wedged between the bit and the side of the hole. The drill string was continually worked with overpulls up to $113,000 \mathrm{~kg}$ for $31 \mathrm{hr}$. With the aid of an explosive charge detonated outside the core bit in open hole, the BHA was eventually freed.

Drilling operations were suspended at Hole 648B after freeing the pipe. After approximately 30 days of drilling and coring in Hole 648B on Leg 109, the hole was deepened to a total depth of $50 \mathrm{mbsf}$. The lack of progress was attributed to having to continually redrill rubble that filled the hole between each bit run. Over $165 \mathrm{~m}$ of rubble was drilled and cored. It required as much time to drill the rubble as it did to make new hole. Had problems with the hole stability abated, the target depth of $200 \mathrm{~m}$ could have been reached based on the penetration rates realized for both the 9-7/8-in. core bits and the 12-1/4-in. drill bits. To continue operations in Hole $648 \mathrm{~B}$, it will be necessary to make a mill run to remove the junk (cone) from the hole. Once the cone has been removed, drilling and coring operations may be resumed cautiously with the use of drilling jars.

\section{Sites 649, 669, 670}

Although Legs 106 and 109 concentrated most of their effort on drilling at Hole 648B, several unsupported "bare-rock" holes were attempted using the positive displacement drilling and coring motors. On Leg 106, 10 shallow holes were drilled into unconsolidated hydrothermal deposits at Site 649. The coring motors worked satisfactorily, but the core retrieval system failed twice. With the exception of one hole (Hole 649B), core recovery was extremely low. This was attributed to the alternating hard and soft formations present in the hydrothermal deposit which could not be trapped by the available core catchers.

On Leg 109, two unsupported spud-in holes were attempted using the PDCM's. At Hole 669, spud-in was attempted in plutonic gabbros underlying a few meters of sediment-rubble. The bit appeared to skid on the gabbro, rather than penetrate it. This problem along with mechanical problems with the PDCM led to abandonment of the hole.

At Hole 670, the PDCM drilling assembly was successfully used to spud-in a hole in serpentinized peridotite underlying 5-7 $\mathrm{m}$ of sediment. After drilling $35 \mathrm{~m}$ into the peridotite body, the PDCM system was tripped out of the hole when problems developed with the core retrieval system. A standard rotary coring system was tripped into the hole and successfully reentered without a reentry cone using the television-sonar system to locate the 4- x 8-ft crater. The hole was drilled to 92 mbsf before the hole was abandoned after approximately 4 days on site. Core recovery ranged from $2 \%$ to $17 \%$.

\section{EVALUATION OF THE PERFORMANCE OF THE NEW CRUSTAL DRILLING AND CORING SYSTEMS}

\section{Hard-Rock Guidebase}

The HRGB provides the lateral support and bit confinement necessary to spud-in a hole in an area with little or no sediment cover. This important engineering development overcomes a major obstacle to drilling at mid-ocean ridges and in other similar environments (back-arc basins, seamounts, etc.). Assembly and deployment of the HRGB can be accomplished in a relatively short period of time (approximately $48 \mathrm{hr}$ ), although the deployment is sensitive to weather conditions. No major engineer- 
ing modifications are required to the HRGB suspension, cementing, or release systems. A means of viewing the seafloor under the guidebase during deployment will be necessary in the future. A smaller, lighter HRGB design may be feasible, but before significantly modifying the design, a second guidebase should be deployed to obtain more operational and engineering data; this is planned during Leg 118 drilling on the Southwest Indian Ridge.

\section{Positive Displacement Drilling and Coring Motors}

Drilling motor technology has proved to be an important tool in establishing scientific boreholes in regions of the oceans where there is little or no sediment cover. The PDMs have adequate torque/weight for unsupported spudding-in of a hole in fractured basalt with voids (hollow pillow), which help to provide adequate bit confinement (Hole 648A). The PDCMs do not appear to have adequate torque/weight for spudding-in a gabbro-type formation with an unsupported BHA (Hole 109669A). In softer formations, such as serpentinized peridotite and hydrothermal vent sediments, where $900-2700 \mathrm{~kg}$ of weight on bit is required, the PDCM unsupported spud-in technique is very effective (Holes 106-649B and 109-670A).

To date, 14 holes have been spudded-in using both the PDM's and PDCM's. The holes have been established in a wide range of lithologies that include young fractured basalts, gabbro, serpentinized peridotite, and hydrothermal sediments. Penetration rates varied considerably with the type of formation being drilled or cored. The use of unsupported (i.e., without a guidebase) drilling motor technology to establish bare-rock holes is feasible in certain types of formations, but should still be considered developmental.

\section{Real-time Television System}

The real-time television system was used for making 18 reentries on Leg 106 and 19 reentries on Leg 109. Seven of the reentries made on Leg 109 were made with a 1-m-diameter cone attached to the bottom of a fishing tool that was lowered onto the top of a BHA protruding above the reentry cone. At Site 670, a hole was spudded-in with an unsupported PDCM assembly. Then, on a later bit run, the open hole was reentered without the presence of any type of seafloor reentry hardware (guidebase, standard reentry cone, or free-fall reentry cone) using the television system on the drill pipe.

The television system is crucial to the many specialized operations involved in bare-rock crustal drilling. It has been demonstrated that utilization of the television system allows precise location of holes relative to seafloor geological features. Reentry into significantly smaller reentry targets (open holes and small diameter reentry cones) can be accomplished but is weather-dependent. These operations should be considered developmental at this stage. It should be noted that the television system is required for setting guidebases on the seafloor and for unsupported drilling and coring operations. Future bare-rock drilling targets are therefore limited to $6000 \mathrm{~m}$ water depth, which is the depth capability of the television system.

\section{Borehole Considerations}

The primary limiting factor in drilling young fractured basalt formations is the lack of hole stability. In 30 days of drilling and coring at Hole 648B during Leg 109, the hole was deepened only $16 \mathrm{~m}$. This lack of progress is attributable almost entirely to having to continually redrill rubble that filled the hole between each bit run. Reduced hole diameters and hole annuluses used on Leg 109 improved hole stability and hole cleaning capability somewhat, compared to Leg 106. Further reduction in hole size below 9-7/8-in. diameter will be required to overcome hole stability problems in fractured basaltic formations.

\section{Drill and Core Bits}

The two new 9-7/8-in. core bit designs used on Leg 109 resulted in a twofold increase in bit life. Core bits used on Leg 106 had an average bit life of $6 \mathrm{hr}$. The new bits deployed in Hole 648B on Leg 109 had a bit life exceeding $12 \mathrm{hr}$. Both type 7 conical and type 75 chisel bit cutting structure designs held up well, but the type 7 conical structure performed best. The 12-1/4-in. Q7JSL tricone bits with a type 7 conical cutting structure also performed well. The tungsten carbide wear buttons and hardfacing applied to the shirttail area and along the leading edge of the bit legs provided considerable wear resistance for both the core bits and the drill bits. The increase in bit life was attributed to these wear protection features.

Although improvements were observed utilizing the 12-1/4in. drill bits and 9-1/2-in. drill collars compared to the Leg 106 operations, considerable torque was still required to effect and maintain rotation to the bit. The sticking hole conditions resulted in continuous stalling of the bit while drilling at 40-60 rpm. It was necessary to drill at bit speeds of $120-180 \mathrm{rpm}$. At this speed the momentum of the large-diameter drill collars helped to maintain rotation. Penetration rates of $1-2 \mathrm{~m} / \mathrm{hr}$ were realized. These penetration rates are considered reasonable in fractured basalt formations; however, debris and fill falling into the hole resulted in a much smaller "effective" penetration rate.

\section{2-1/4-in. Pack-Hole Drilling Reaming Assembly}

The 12-1/4-in. reamer assembly used with the 9-1/2-in. drill collars and the 12-1/4-in. Q7JSL drill bit appeared to help minimize hole disturbance. The reamer assembly allowed the bit to run smoothly while reaming the existing 12-1/4-in. hole and drilling out the cement. When the bit-reamer assembly encountered undrilled rock, it was noted that excessive torque was required to maintain bit rotation. It therefore is questionable if this type of drilling assembly could be used safely for making a new hole without having the BHA adequately supported.

\section{Drilling Jars}

Both the mechanical and hydraulic drilling jars lacked sufficient strength for aggressive drilling when unsupported above the seafloor. A hydraulic and a mechanical jar failed in the hole, resulting in two time-consuming fishing operations. Any future drilling requiring the use of jars above the seafloor will necessitate the development of a costly set of special drilling jars.

\section{Specialized Cementing Techniques}

The cement plugs were judged effective in preventing the hole from caving in when the bits were pulled from the hole. The cement plugs provided enough stabilization to the upper part of the hole to allow limited coring operations. The cement plugs also provided enough temporary stability to allow casing to be run to 28 mbsf successfully. Had the cementing techniques not been used, coring operations would have been suspended in Hole 648B much earlier in the leg.

\section{Core Recovery}

The recovery rate coring fractured basalt in Hole 648B averaged $14 \%-15 \%$ on both Legs 106 and 109 . Lower recovery rates are attributed to jamming of the core barrel with rubble. The majority of the hard-rock coring in Hole 648B was done with the proved rotary coring system. Improving core catcher design and maximizing core recovery is a continuing concern at ODP for all coring systems. Through design improvements on existing catchers and future development work, some improvement in recovery of fractured rock can be realized. Regardless of the core catcher design used, recovery rates are expected to remain 
low $(15 \%-25 \%)$ due to inherent jamming problems associated with coring fractured rock.

\section{RECOMMENDATIONS FOR FUTURE HARD-ROCK DRILLING}

Although drilling in young crust is now technically feasible, the major scientific objectives of crustal drilling will not be achieved unless penetration and recovery rates can be substantially improved. The utilization of the HRGB and drilling motor technology has proved to be an effective means to spudding-in a hole on hard rock with only minimal support for the BHA. The drilling techniques used thus far have also provided reasonable penetration rates of $1-2 \mathrm{~m} / \mathrm{hr}$. The most limiting factor in drilling young fractured basalt formations is the lack of hole stability. An effective solution to this problem will require major engineering effort to design a new drilling system adapted to this difficult drilling environment. A number of short- and longterm options are currently being considered.

Short-term development ( $<3$ years) options are:

1. Redesign drilling jars to operate in more unsupported situations to get the drill string freed when hole caving causes stuck pipe.

2. Use small hole diameters (9-7/8 in.) and drilling techniques that minimize hole disturbance (avoid hole-opening operations).

3. Pump in cement plugs on selected bit runs (application already proved on Leg 109).

4. Select more stable bare-rock formations to drill so as to gain initial drilling experience before tackling more fractured, rubbly formations.

Long-term development (3-5 years) options are:

1. Coring smaller holes with high-speed diamond bits powered by downhole motors/turbines (adaptation of small-kerf mining technology).
2. Improving techniques for cutting and rubble removal from hole, including use of specialized drilling mud.

3. Developing side-wall coring techniques to improve the representativeness of the recovered material.

The mining concept currently being pursued is the adaptation of a small-kerf wireline mining coring system. In practice, a small-diameter mining drill string is run inside the 5 -in. drill pipe to the seafloor. The mining string would be rotated at the surface with the 5 -in. drill pipe functioning as a riser to the ship. The cores would be wireline-retrievable through the mining string, recovering a $63.5-\mathrm{mm}$ (2.5-in.) diameter core. Advantages of a system of this type are less hole disturbance (because of hole diameter less than 4 in.), improved core recovery, higher penetration rates, and enhanced hole cleaning with cuttings being returned to the ship. An alternate method also being pursued is driving the mining core barrel downhole with a drilling motor.

The long-term development effort requires a significant commitment of manpower and resources. Before expending significant funds and engineering time for the development of a particular hard-rock coring system, an intermediate drilling test program on land should be considered. Assuming that a representative fractured/hard-rock drilling site can be located, a land drilling rig could be made. Petroleum and mining systems under consideration for adaptation to crustal seafloor drilling and coring systems could be evaluated before allocating expensive ship time for testing at sea. Evaluation of modifications (yet to be made) to existing ODP hard-rock drilling systems (PDCM and $\mathrm{RCB}$ ) could also be done on land. Then, upon identifying a system or several systems that perform well at the land test site, significant funds and engineering time could be committed to development and adaptation of improved hard-rock coring systems for deployment at sea. Low-cost land-rig testing should result in considerable cost savings as well as in allowing significant progress to be made developing effective hard-rock drilling techniques and tools in a shorter time. 